\title{
CRASHWORTHINESS ANALYSIS OF THE JANUARY 26, 2005 GLENDALE, CALIFORNIA RAIL COLLISION
}

\author{
Daniel Parent \\ David Tyrell \\ Karina Jacobsen \\ Kristine Severson \\ Volpe National Transportation Systems Center \\ United States Department of Transportation \\ Cambridge, Massachusetts, USA
}

\begin{abstract}
In Glendale, California on January 26, 2005, impact with an SUV on the track caused a southbound commuter train to derail, impact a standing freight train, buckle laterally outward, and rake the side of a northbound commuter train. Significant deformation resulted in the front of the southbound train and the side of the northbound train. There were a total of eleven fatalities and over one hundred injuries. This incident was investigated as a part of an ongoing field study of occupant injury in passenger train collisions and derailments currently being conducted by the United States (US) Department of Transportation's (DOT) Rail Accident Forensic Team in support of the Equipment Safety Research Program of the Federal Railroad Administration (FRA). The Forensic Team determined that the primary causal mechanism of injuries and fatalities in the Glendale incident was the loss of occupied volume of the passenger cars brought about by severe structural deformation.
\end{abstract}

\section{INTRODUCTION}

The Volpe National Transportation Systems Center (Volpe Center) has been supporting FRA's Equipment Safety Research Program by performing rail passenger equipment crashworthiness research. The overall objective of this research is to develop strategies for incrementally improving structural crashworthiness and occupant protection. The structural crashworthiness research involves both building an understanding of the performance of rail equipment and researching strategies for improving preservation of the occupied volume of the passenger rail vehicles. If the occupied volume of the rail vehicle is compromised, serious injuries or fatalities may not be prevented. Once the occupied volume is preserved, strategic modifications to the interior structures can further improve occupant protection.

As part of this effort, a field study of occupant injury during rail collisions and derailments is currently being conducted. As opposed to passenger train accident investigations conducted by the National Transportation Safety Board (NTSB), of which the main objective is to determine the probable cause of the incident, the primary objective of the FRA field study is to determine the causal mechanisms for the injuries and fatalities sustained by the occupants of the train. The information collected by the Forensic Team is used to identify the areas where occupant protection strategies can reduce the risk of injury, such as the design of specific interior features. The execution of this field study requires on-site investigations of collisions or derailments. Twelve such investigations have been conducted to date.

The causal mechanisms for injury generally fit into two categories: loss of occupied volume and secondary impact. Injuries caused by loss of occupied volume occur when there is a large magnitude of structural deformation, or crush, of the railcar. This crushing occurs as a result of impact with another rail vehicle or other right-of-way obstruction, and is known as the primary impact. Equipment designed for crashworthiness can be effective at absorbing and distributing the primary impact energy, which can limit crush to unoccupied areas of the car to mitigate these injuries. One such design, referred to as crash energy management (CEM), has been developed and 


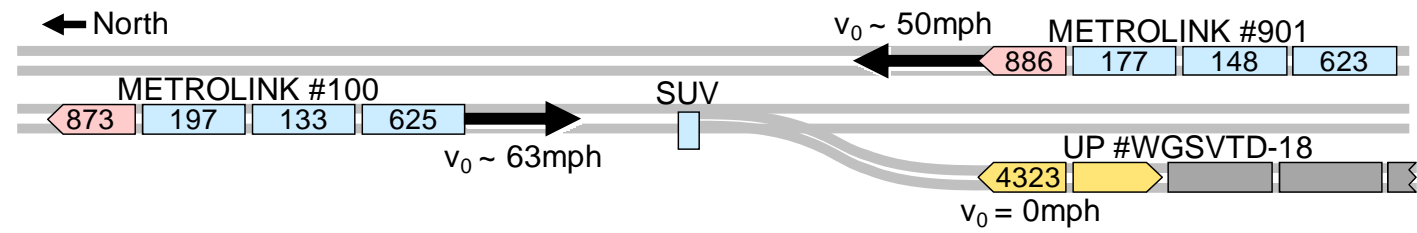

Fig. 2. INITIAL CONFIGURATION OF THE TRAINS INVOLVED IN THE GLENDALE, CA COLLISION

tested for single-level vehicle applications [1], and a multi-level system is currently under development [2].

The rail vehicle will decelerate abruptly as a result of this primary impact, which causes the occupants to impact the seats, tables, or other structures on the interior of the vehicle. These impacts, known as secondary impacts, can cause lifethreatening injuries. Using information collected in the field study investigation, the injuries sustained by passengers can be correlated with the interior layout of the car, the initial position of the occupants, and the design of the seating arrangements. Once a correlation is found, steps can be taken to mitigate the injury risk associated with the seating arrangement. As an example, the investigation of the collision in Placentia, California indicated that workstation tables contributed to the fatal injuries sustained by two passengers [3]. A proof-ofconcept table that reduces the risk of thoracic and abdominal injury during collisions and derailments has been designed, developed, and tested $[4,5]$. Subsequently, workstation tables designed to absorb energy were required and provided as part of a new procurement of METROLINK commuter cars.

\section{GLENDALE, CALIFORNIA}

The rail collision that occurred on January 26, 2005 in Glendale, California was investigated as part of the aforementioned field study. A total of eleven fatalities and over one hundred injuries resulted from this tragic incident. The collision started with a sport-utility vehicle (SUV) which had been placed on the train tracks [6] and involved two passenger trains and one freight train (Fig. 2). Southern California Regional Rail Authority (METROLINK) train number 100 was a southbound passenger train, subsequently referred to as the Southbound train, traveling on the westernmost track in a cabforward orientation. Cab car 625 was leading, coach cars 133 and 197 were following, and locomotive 873 was propelling from the rear. METROLINK train number 901 was a northbound passenger train, subsequently referred to as the Northbound train, traveling on the easternmost track in a locomotive-forward orientation. Locomotive 886 was leading, coach cars 177 and 148 were following, and cab car 623 was on the trailing end. Union Pacific Railroad Company train number WGSVTD-18, led by the north-facing locomotive 4323, was standing on a siding track waiting to deliver ballast to repair track damage caused by mudslides further north.

In the following sections, a reconstruction of the series of events that transpired is recounted in twelve phases. A diagram is included for each phase, which indicates the numbers by which the individual cars are referenced in the narrative. Directional descriptions (such as front, back, left, or right) are described relative to the original direction of travel of the respective vehicle.

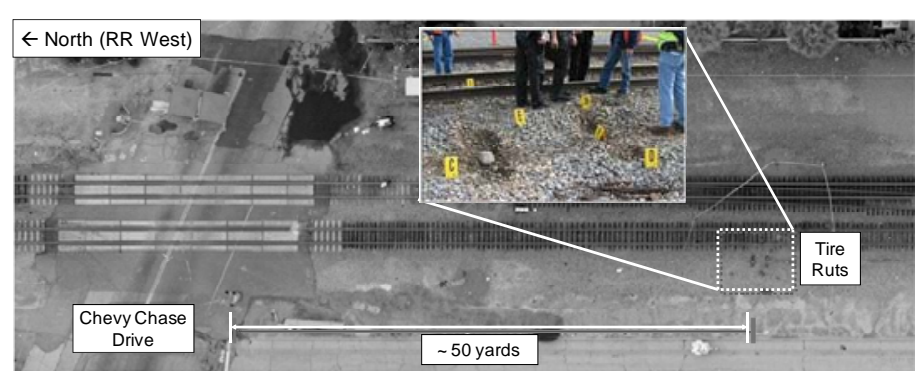

Fig. 1. TIRE TRACKS LEFT BY THE SUV SOUTH OF CHEVY CHASE DRIVE GRADE CROSSING

\section{PHASE 1: FIRST INTERACTION - SOUTHBOUND PASSENGER TRAIN IMPACTS SUV}

The catalyst for this series of events was the SUV, which entered the right-of-way at the Chevy Chase Drive grade crossing and proceeded to drive roughly fifty yards south. The vehicle, identified as an early model Jeep Cherokee Sport, then drove up onto the westernmost track such that the vehicle was facing perpendicular to the track, with the front tires between the rails and the rear tires on the right-of-way. Fig. 1 shows two ruts that were dug in the ballast. Reports from the scene indicated that the driver had exited the vehicle as the southbound train approached, leaving the Jeep on the track [6].

Debris from the Jeep was found south of the point where the tire ruts were located, and there was notable damage to the ties of the westernmost track starting two ties south of the ruts. The Jeep was damaged significantly during this impact, spewing debris along the right-of-way as the passenger train pushed it down the track. As the mass of a Jeep is significantly less than that of a passenger train, the speed of the passenger train was not noticeably affected by this impact. However, the large portion of the remains of the Jeep traveled down the track with the southbound train, and it is believed to have interacted with the lead truck of car 625 .

As the southbound passenger train continued down the track, it reached a facing-point switch roughly 300 yards from the Chevy Chase Drive grade crossing. This switch connected the main track to a siding track to the west. As the lead truck of the cab car of the southbound passenger train crossed this switch, it entered the siding track. Based on the damage to the clips and ties of the siding track, it is believed that the rear truck of the cab car remained on the main track, and the cab car traveled down the track at an angle. Though the emergency brakes were applied, the southbound train was unable to stop before it reached the freight locomotive. 
PHASE 2. SECOND INTERACTION - SOUTHBOUND PASSENGER TRAIN IMPACTS FREIGHT TRAIN

The southbound train impacted the lead locomotive of the stationary freight train at a speed of approximately 47 miles per hour. With the front truck on the siding track and the rear truck on the main track, the cab car of the southbound passenger train was aligned so that the left collision post contacted the center of the lead freight locomotive, as indicated by local deformation of the locomotive anti-climber and short hood. Deformation of the breastplate of the locomotive left of center indicates impact by the coupler of the cab car, further confirming the orientation of the cab car.

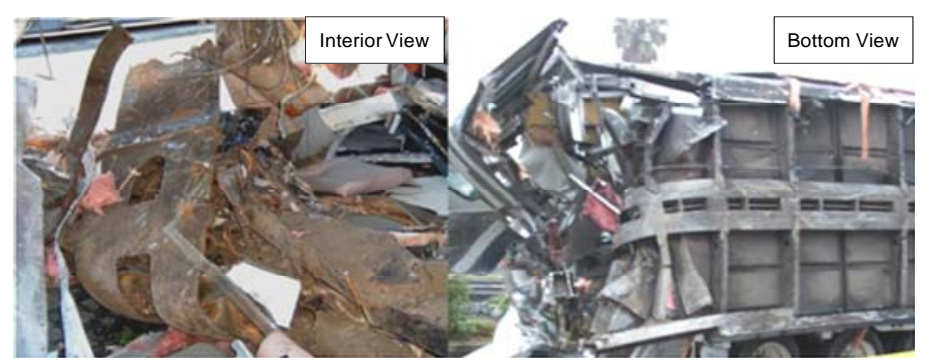

Fig. 4. DEFORMATION OF THE CENTER FRAME OF THE CAB CAR OF THE SOUTHBOUND PASSENGER TRAIN

Upon impacting the locomotive, the front of car 625 underwent gross structural buckling and crushed roughly 26 feet. The mode of deformation of the center frame of the cab car suggests that the locomotive overrode the cab car (Fig. 4), as the gooseneck portion of the center frame aft of the body bolster bent into an "S"-shape. Additionally, a fire consumed some portions of the lead end of the cab car, though it is unclear whether this fire began at initial impact with the highway vehicle or during the interaction with the cab car and the freight locomotive. The interaction of the southbound cab car and the freight locomotive, in turn, lifted the freight locomotive off of the tracks, rotated it thirty degrees with respect to the locomotive it was coupled to, and dropped it on its side on a parking lot adjacent to the siding track. Impact with the parking lot caused lateral deformation of the roof and engineer's compartment of the locomotive. Saw-tooth buckling initiated in the trailing cars of the southbound train, and escalated to larger-scale lateral buckling in the connection between the cab car and the first coach car. The rear truck of car 625 and the front truck of car 133 both derailed and rotated such that the neck of the coupler shaft of car 625 fractured and the cars uncoupled.

\section{PHASE 3. THIRD INTERACTION - SOUTHBOUND TRAIN IMPACTS NORTHBOUND TRAIN}

The rear of car 625 and the front of car 133 began to rotate towards the northbound tracks, just as the northbound train was traversing though the area at roughly 50 miles per hour. The rear left corner of car 625 and the front left corner of car 133 impacted the rear two cars of the northbound train. The impact initiated about 10 feet aft of the front door of car 148, and raked the entire side of the car. This raking caused severe deformation of the sidewalls of car 148, penetrating up to the aisle of both the upper and lower level of the car and destroying several rows of seats (Fig. 3). As the raking continued along the side of the car to the body bolster, where the side sill of the car increases in height to transition between the lower level and the mezzanine level, the amount of intrusion decreased since this structure offered more resistance to crush than the sidewall alone. This interaction caused car 148 to derail, and markings on the side of the car indicate that

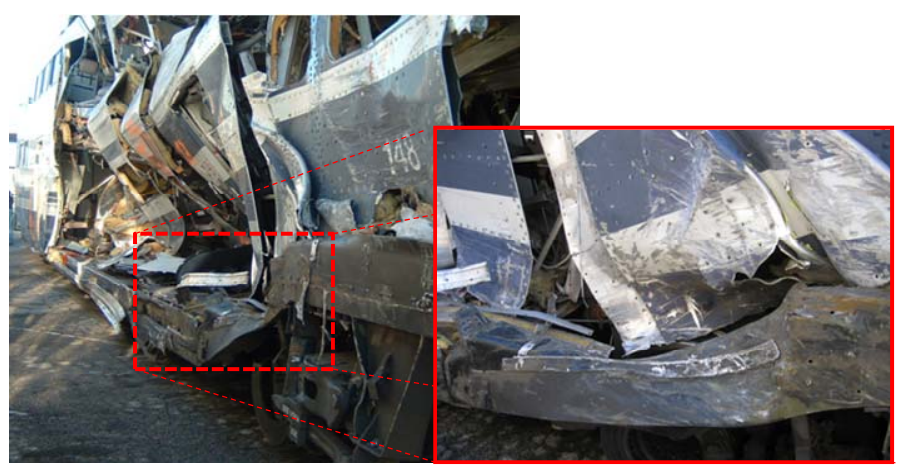

Fig. 3. DAMAGE TO THE SIDE SILL AT THE BODY BOLSTER OF CAR 148 OF THE NORTHBOUND TRAIN

the car body rolled to its right and nearly fell on its side.

As car 148 had rolled to its side, car 623 remained mostly upright, exposing its left front corner as car 148 rolled to its right. As the ends of cars 625 and 133 reached the front of car 623 , the impact was severe enough to compromise the occupant compartment and cause cars 623 and 148 to decouple. As car 623 separated and began to roll to its right side, the rest of the northbound train uncoupled and continued up the track. The interaction of the jackknifed ends of cars 625 and 133 continued as car 623 was in the process of rolling, which is evident in the damage to the lower portion of the sidewall and the local deformation of the side sill just in front of the body bolster (Fig. 5).

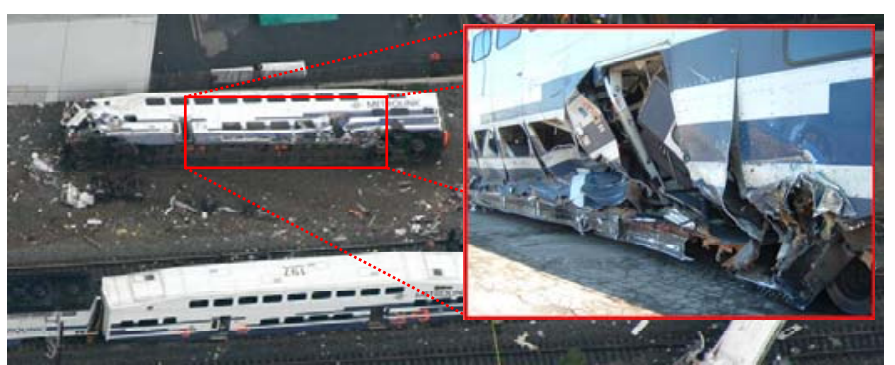

Fig. 5. DAMAGE TO THE NORTHBOUND CAB CAR 623 AS A RESULT OF IMPACT WITH CARS 133 AND 625 OF THE SOUTHBOUND TRAIN

As with car 148, the penetration into the side sill stops at the body bolster of car 623 , suggesting that the car was pushed off of the track at this point. Car 623 then rotated completely onto its side and slid down the right-of-way. In the process, its lead truck detached and landed upright. The final resting position of the rail vehicles is shown in schematic in Fig. 6. 


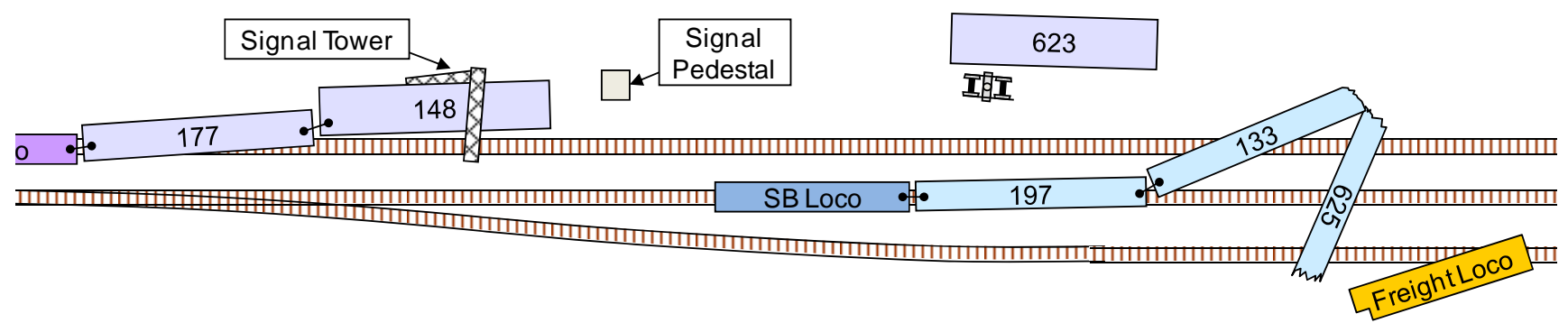

Fig. 6. FINAL RESTING POSITION OF THE EQUIPMENT IN THE GLENDALE, CA RAIL COLLISION

\section{VEHICLE STRUCTURES}

In the Glendale collision, there was a significant loss of survival space due to three modes of deformation: bulk crushing of the front of the lead cab car, end frame deformation during the raking collision, and sidewall intrusion during the raking collision. This loss of survival space is quantified based on the total area of potentially occupiable space damaged or destroyed during the collision.

\section{CAB CAR CRUSH}

The location that experienced the greatest amount of structural deformation was the front end of the cab car (625) of the southbound train. Unlike typical single-level passenger cars which have a continuous horizontal center sill that spans the entire length of the vehicle, the center sill of the multi-level cars in the METROLINK fleet is raised at either end and lowered inboard of the body bolsters (Fig. 8). The transition area between the two levels is referred to as the gooseneck. When loaded in compression, the offset nature of the distal ends of the structure creates a moment at the gooseneck, thus a plastic hinge can form at one of these transition areas and can result in gross structural deformation. Such deformation has occurred in previous collisions, such as the Placentia, California rail collision that occurred in April 2002 [3, 7].

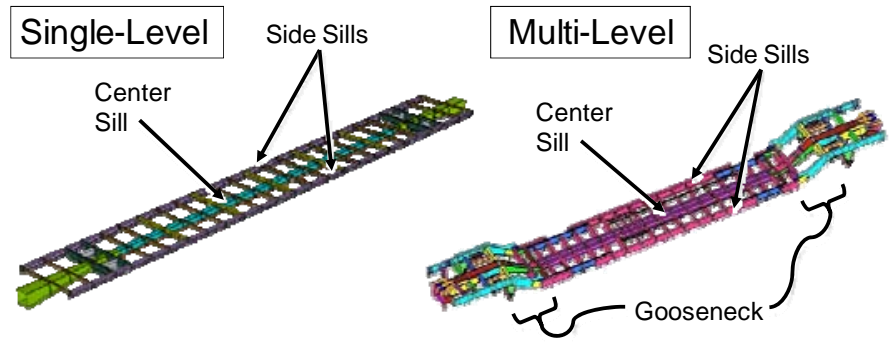

Fig. 8. COMPARISON OF SINGLE-LEVEL AND MULTILEVEL CAR BODY STRUCTURES

Deformation of the center beam at the gooseneck structure occurred at two plastic hinges (Fig. 7). These hinges formed due to the moments created in the process of reacting against the collision force, which is likely to have exceeded 4 million pounds. Rotation about these hinges produced large amounts of longitudinal, as well as lateral, deformation of the car body structure. The longitudinal deformation resulted in roughly 26 feet of crush, which encompassed the entire forward mezzanine (or intermediate) level and the first three to four rows of seats on the upper and lower levels.

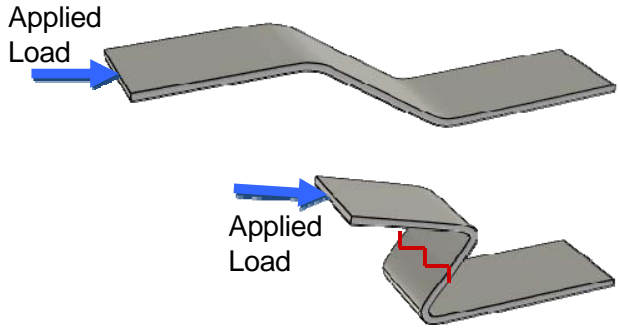

Fig. 7. SCHEMATIC OF THE DEFORMATION TO THE GOOSENECK OF THE FRONT OF CAB CAR 625

\section{END FRAME DEFORMATION}

There was significant end frame damage in three of the cars involved in the Glendale collision. Any inward deformation results in an immediate loss of survival space, as there are seats directly adjacent to the walls that span the collision and corner posts on the interior of these multi-level cars.

As the trailing end of cab car 625 and the leading end of coach car 133 raked the northbound train, significant damage to the end frames occurred (see Fig. 9 and Fig. 10). The primary mode of deformation of the rear end frame of car 625 was shear at a roughly thirty-degree angle from lateral. The left corner

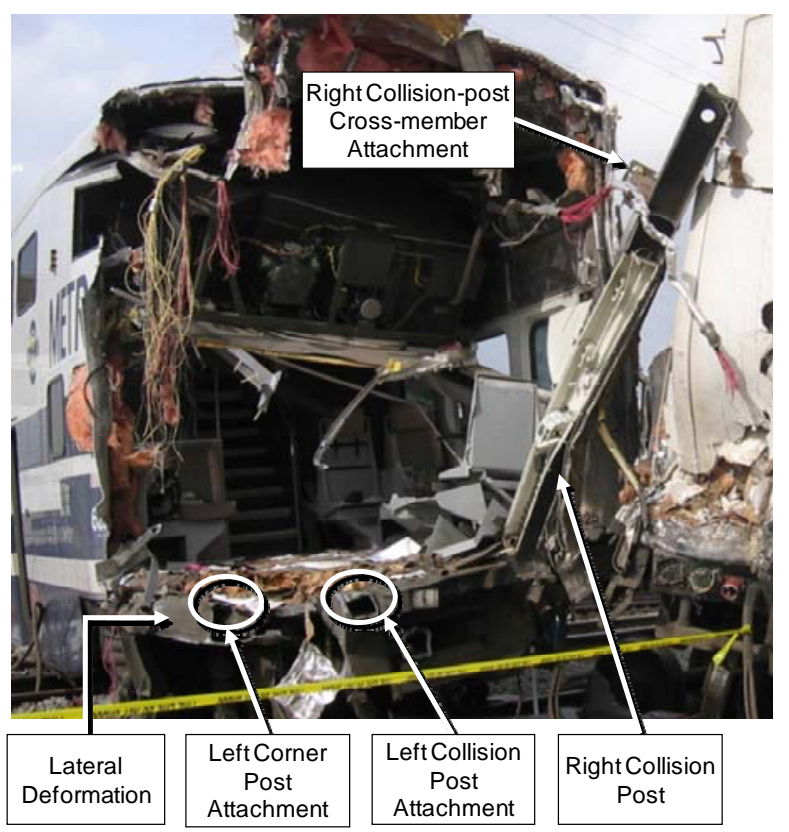

Fig. 9. DAMAGE TO THE TRAILING END FRAME OF CAB CAR 625 OF THE SOUTHBOUND TRAIN 
and collision posts detached completely from the end frame structure. The right collision post remained attached at the base, though the top detached from the roof structure (Fig. 9). The right corner post remained mostly intact.

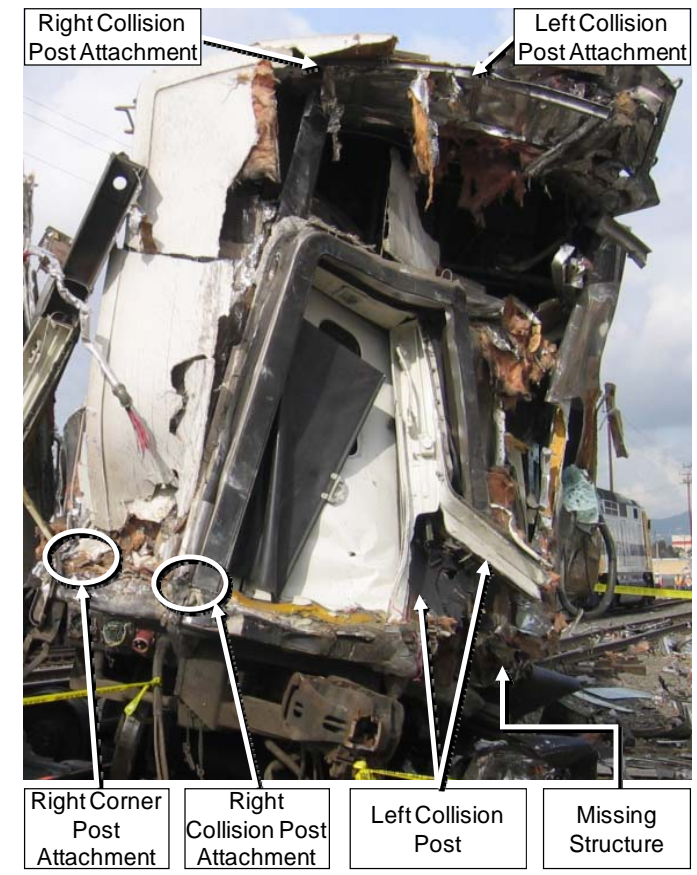

Fig. 10. DAMAGE TO THE LEADING END FRAME OF COACH CAR 133 OF THE SOUTHBOUND TRAIN

The mode of deformation of the end frame of car 133 was also shear, but at an angle closer to halfway between longitudinal and lateral due to the geometry of the impacting vehicles. The right corner and collision posts remained attached at the floor and room, though there was some deformation due to the interaction with the rear of car 625 and the connection to the left collision post. The left collision post was fractured roughly two feet from its base, detached from the roof connection, and deformed into the occupied volume (Fig. 10). Interaction of the jackknifed ends of cars 625 and 133 caused car 148 to list to its right side, exposing the left front corner post of car 623. Upon impact, the corner post fractured near its vertical midpoint (Fig. 11).

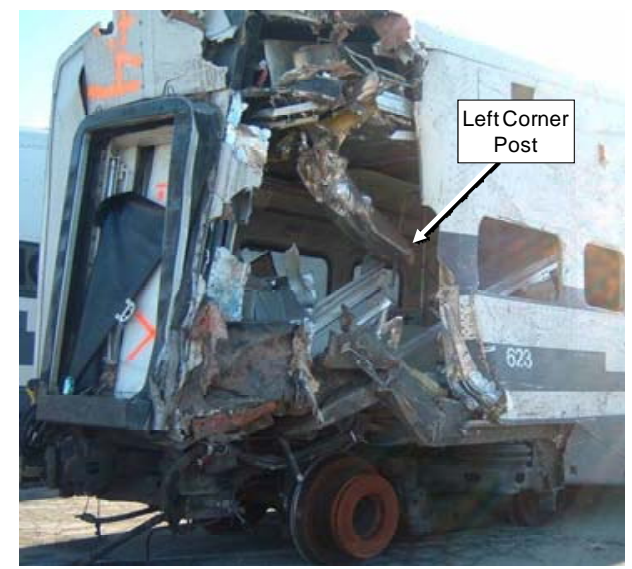

Fig. 11. DAMAGE TO THE FRONT CORNER POST OF CAR 623

\section{SIDE WALL INTRUSION}

The interaction of the end frames of cars 625 and 133 of the southbound train caused significant intrusion into the sides of cars 148 and 623. The maximum intrusion occurred in the middle of car 148, where the crush reached the aisle of both the lower and upper levels. The intrusion decreases at the point where the side sill transitions from the lower level to the mezzanine level, where there are signs of a significant impact in both coach car 148 (Fig. 3) and cab car 623 (Fig. 5).

\section{LOSS OF SURVIVAL SPACE}

Both passenger trains were comprised of multi-level cab and coach cars manufactured by Bombardier, which have three seating areas: lower, upper, and intermediate, or mezzanine. There are about 34 seats (seating arrangements differ slightly based on the build generation of the car) in the lower level, 19 seats in each mezzanine level, and 72 seats in the upper level of each car. Some facing-seat arrangements in the upper and mezzanine levels include intervening workstation tables. In the leading end of a cab car, the mezzanine level includes 4 fewer seats to accommodate the cab engineer's control stand.

To quantify the severity of the damage to the interior of the passenger trains, the amount of space lost due to bulk crushing or accumulation of debris is estimated in square feet. This quantification is referred to as loss of survival space, as it is assumed that a passenger initially positioned in this space would not have survived the forces large enough to bring about structural deformation of the rail vehicle. This is a conservative estimate, as typically not all of the survival space is occupied. Also, occupants initially seated in these areas can be pushed out of the way without sustaining serious injuries.

The largest loss of survival space occurred in car 625 of the southbound passenger train, where there was roughly 26 feet of crush at the front of the car and additional shearing at the trailing end. The front mezzanine level was lost entirely, along with its fifteen seats. Debris from the mezzanine level was pushed back into the lower level, destroying seven seats and damaging six others. In the upper level, the front fourteen seats were lost and an additional four seats were damaged. In the right corner of the rear mezzanine level, eight seats were lost and two others were damaged. In the front corner of car 133, the second car in the southbound passenger train, four seats were lost and two others were damaged. The loss of survival space for cars 625 and 133 of the southbound train is summarized in Fig. 12.

The raking of the northbound train resulted in a significant loss of survival space in cars 148 and 623. In car 148, a total of 18 seats were lost and 16 seats were damaged. The upper level was the most affected, losing 95 square feet of survival space, while the lower level lost almost 80 square feet and the rear mezzanine level lost 5 square feet. In car 623, the front right corner lost 11 square feet of survival space, including six seats, while two other seats were damaged. The lower level of car 623 lost 10 seats and 40 square feet of survival space. The loss of survival space for cars 623 and 148 of the southbound train is summarized in Fig. 12. 

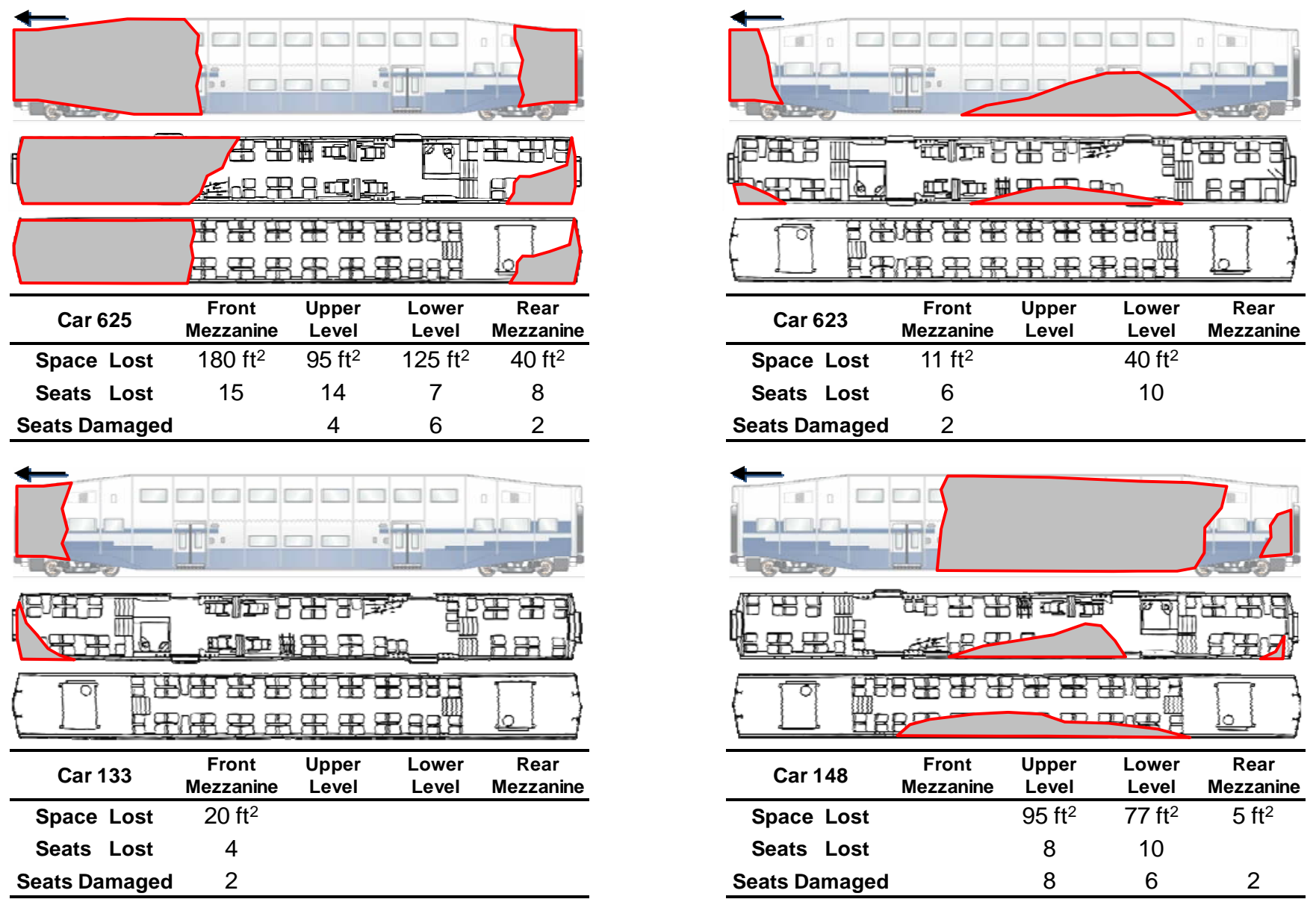

\section{Fig. 12. LEFT: SOUTHBOUND TRAIN; RIGHT: NORTHBOUND TRAIN}

Overall, there were 82 seats lost, 32 seats damaged, and a total of 688 square feet of survival space lost out of an estimated 8,000 square feet of floor space for all of the passenger equipment involved.

\section{DAMAGE TO INTERIOR STRUCTURES}

Damage to the interior seats, tables, and stanchions resulted from both structural deformation of the railcar and from occupant impact. A majority of the damaged interior structures were located in areas of intrusion into the occupant volume, such as in the rear of car 625 (Fig. 13, top left) where the seat pan was broken and torn from its mounting bolts by debris from the interaction with the side of cars 148 and 623. Another example occurred on the upper level of car 625, where the front half of the seat pan of two forward-facing seats had broken off at the point of attachment to the seat base (Fig. 13, top middle). This likely resulted from the bulk crushing or accumulated debris from the crushing of the front mezzanine level, as these seats were located at the point of maximum crush.

In areas where the occupant volume was not compromised, damage to the interior structures due to impact by unrestrained, seated occupants was less severe. One common sign of impact was cracking at the transition between the seat bottom and the seat back (Fig. 13, bottom left, middle). Another common sign of impact was separation and cracking of the seat shell at the transition between the headrest and the seatback (Fig. 13, bottom right). While these failures can present sharp edges to the occupants, there is no indication that these sharp edges resulted in severe injury.

In roughly eight seating arrangements in each car (four in the upper level and two in each mezzanine level, though these numbers vary depending on the generation of the vehicle and the state of interior refurbishment), a workstation table is installed between pairs of facing seats. Previous studies have indicated that this workstation table, while helping to compartmentalize occupants in an collision, presents a risk of traumatic abdominal injury [3, 8]. Several tables were displaced from their original positions, some due to structural deformation of the wall or floor to which the tables are attached, and some due to occupant impact (Fig. 13, top right). There were several signs of abdominal injury due to such impacts, though none of these injuries was critical.

\section{COLLISION DYNAMICS}

Using the evidence available from the on-scene investigation, the dynamics of the collision can be analyzed in more detail. This evidence includes measurements of the final resting position of the vehicles involved and data from the event recorders in the locomotives and cab cars from each train. The objective of this effort was to assess the severity of the occupant environment by determining the risk of occupant 

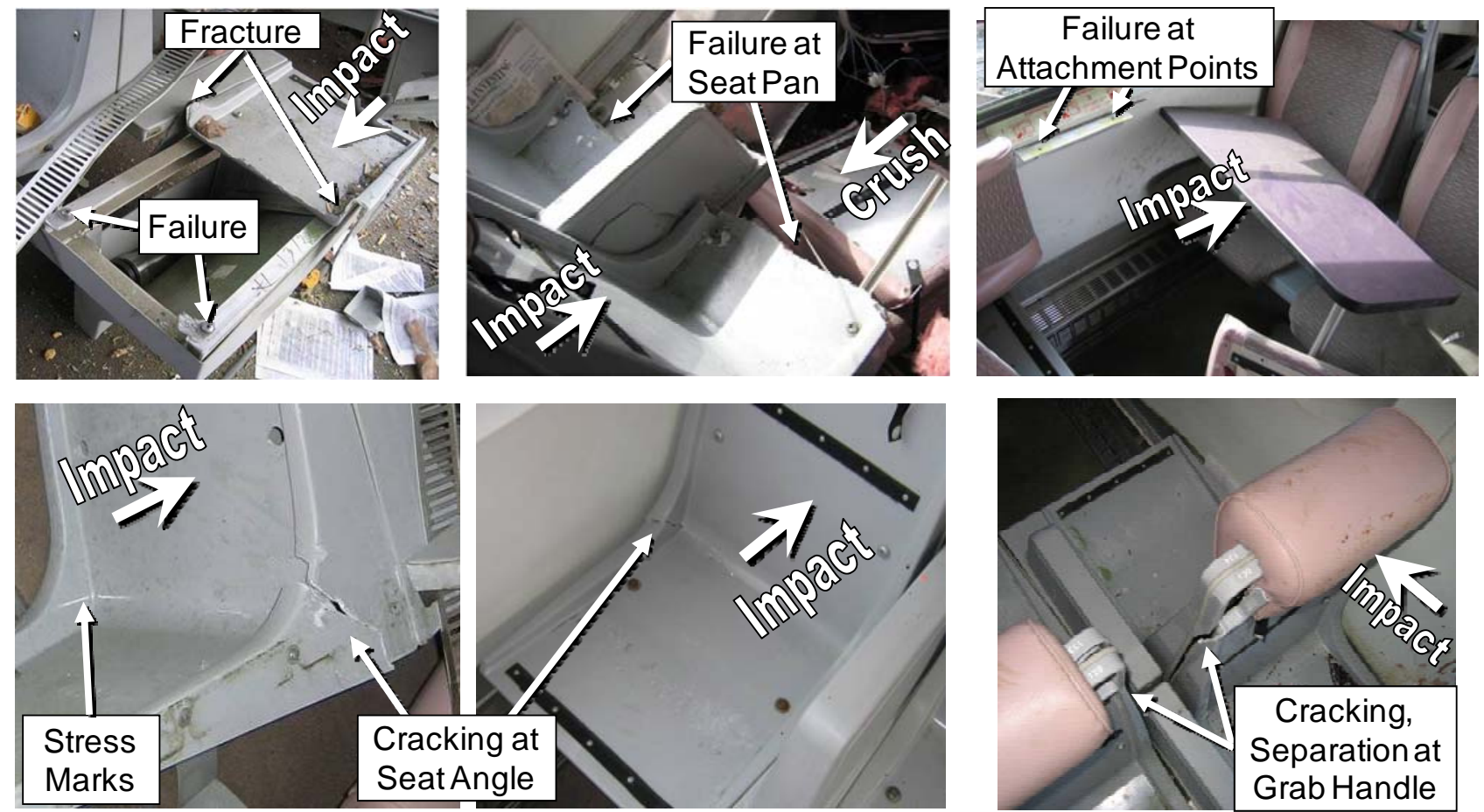

Fig. 13. DAMAGE TO THE INTERIOR OF THE PASSENGER CARS

injury due to secondary impact with interior structures such as seats and tables. The event recorders from both trains included essential information to assist in the understanding of the collision dynamics. The impact speeds can be determined, and the average decelerations can be calculated, from this data.

\section{SOUTHBOUND PASSENGER TRAIN}

Fig. 14 shows a velocity-time history of the cab car and locomotive in the southbound passenger train. The train was traveling just above 80 miles per hour when the conductor spotted the SUV on the track, at which point the emergency brakes were applied. During the impact with the SUV, it appears that the lead axle of the cab car (the typical location of velocity measurement) stopped spinning, as the velocity drops abruptly. According to the event recorder data, the locomotive then continued at a mostly constant deceleration of 1.5 miles per hour per second until the cab car impacted the freight locomotive. At this point, the speed reported by the southbound locomotive dropped from 47.3 miles per hour to 0.9 miles per hour in one second, which would have required a deceleration of 2.1 times the acceleration due to gravity. However, it is possible that this change in speed occurred over a smaller time interval than the one second sample time of the event recorder, thus the deceleration of 2.1g is a lower bound on the severity of the occupant environment. As a point of comparison, an $8 \mathrm{~g}$ peak deceleration pulse is used in the standard for the development of seats for commuter rail service.

While the longitudinal accelerations were relatively benign, the secondary impact environment was exacerbated by the presence of vertical and lateral motions as well as yaw and roll of the passenger cars. During the collision, both the cab car (625) and first coach car (133) underwent significant rotation about a vertical axis as they ended up 110 degrees and
18 degrees, respectively, from their original orientations. The mode of deformation of the cab car (625), as well as the kinematics of the standing freight locomotive, likely drove the front end of the cab car downward resulting in an upward acceleration of the occupants relative to the interior structures of the car. These lateral and vertical accelerations could potentially allow the occupants to enter the aisle or override the seatbacks, subsequently resulting in a higher secondary impact velocity and in a vulnerable body position.

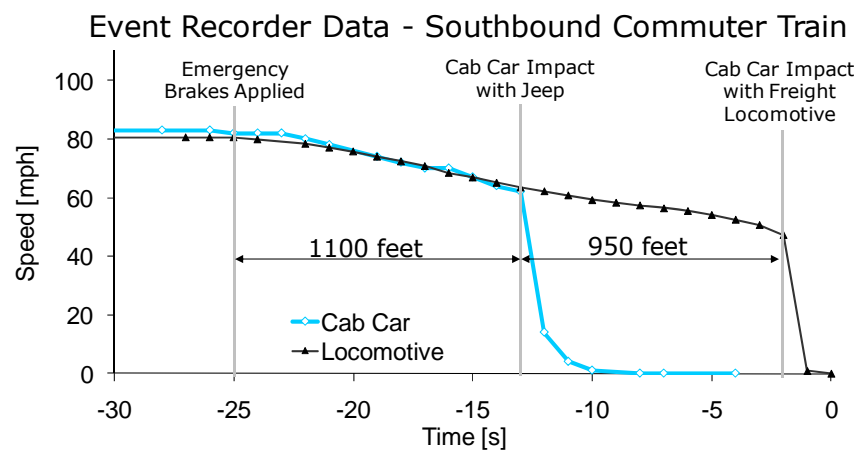

Fig. 14. SPEED-TIME HISTORY OF THE LEAD CAB CAR AND TRAILING LOCOMOTIVE IN THE SOUTHBOUND PASSENGER CONSIST

\section{NORTHBOUND PASSENGER TRAIN}

In the northbound passenger train, the longitudinal acceleration pulse was less severe than in the southbound train. According to the event recorder in the northbound locomotive (Fig. 15), the forward cars in the consist that remained coupled stopped from around 53 miles per hour in roughly 11 seconds, an average deceleration of 5 miles per hour per second or about one quarter of the acceleration due to gravity. This level of deceleration is slightly more severe than emergency braking 
alone, since car 148 was partially on its side and being dragged through ballast. Thus, the secondary impact injury risk to the passengers in cars 148 and 177 due to the longitudinal acceleration pulse alone is extremely low.

The trailing cab car in the northbound commuter train, which decoupled during the interaction with the southbound train, stopped more abruptly than the cars that remained coupled. Unfortunately, data from the event recorder are unavailable after the time of impact. The coupled cars continued two car lengths, or about 160 feet, farther than the trailing cab car. This accounts for roughly one half of the distance traveled by the northbound train after the impact. Therefore, the deceleration of the trailing cab car is likely to have been twice as high as that of the cars that remained coupled to the locomotive, which is still relatively low compared to the acceleration due to gravity.

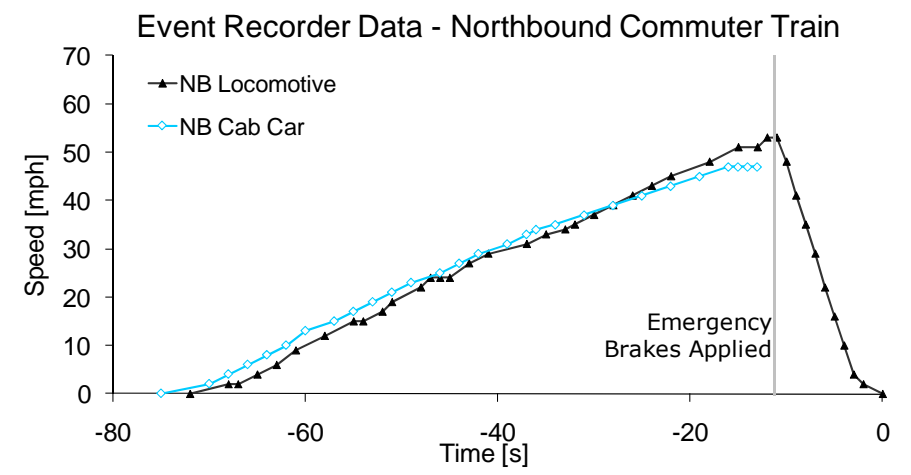

Fig. 15. SPEED-TIME HISTORY OF THE LEAD LOCOMOTIVE AND TRAILING CAB CAR OF THE NORTHBOUND PASSENGER TRAIN

Similar to the southbound passenger train, off-axis acceleration components were present in the occupant environment in the northbound train. As the ends of the cars 625 and 133 in the southbound train raked the northbound train, the cars were pushed laterally and rolled to their right. Car 148 came to rest at a 45-degree angle, though evidence suggests that its peak rotation may have been as much as 90 degrees. Car 623 decoupled from 148 and rolled a full 90 degrees and landed on its right side. This presents a severe occupant environment, since the occupants were likely pushed towards the left side of the car, then dropped up to 10 feet to the ground as the car tipped onto its side.

\section{OCCUPANT RESPONSE}

\section{FATALITIES}

All eleven fatalities that occurred in the Glendale, California rail collision were a direct result of lost survival space. Eight fatalities occurred on the southbound passenger train, seven of which resulted from the impact of the southbound passenger train with the standing freight locomotive. These passengers were seated in the front mezzanine level of the cab car, which was completely lost in the collision. The injuries sustained by these passengers included massive blunt trauma, severed limbs, and lacerations indicative of bulk crushing of the occupied area of the car. One passenger who sustained fatal injuries was initially located in the rear mezzanine level, and was ejected out the back of the car during the raking impact with the northbound commuter train. Evidence at the scene suggests that this occupant was directly impacted by car 623 .

Three of the fatalities occurred on the northbound train. One fatality was the conductor of the northbound train, who was located in the front mezzanine level of car 623 where there was significant intrusion into the occupant volume. Two fatalities occurred on the left side of car 148, one on the upper level and one on the lower level, in the area that was heavily damaged by the raking impact and subsequent intrusion into the side of the car. It was suggested by the coroner that one of these fatalities occurred in car 623, but some of his belongings were found on the upper level of car 148.

\section{INJURIES}

A total of 124 passengers were transported to medical facilities, though medical records were available for only 103 of these passengers. Thirty of the passengers were admitted for further treatment. Injuries sustained by the passengers were coded based on the guidelines of the 2005 update of the Abbreviated Injury Scale (AIS) [9]. Considering the most severe injury to each passenger for whom medical records were available, a majority of the injuries were minor to moderate, and only isolated cases were serious, severe, or critical (Table 1).

\section{Table 1. INJURIES BY MAXIMUM AIS SCORE OF} EACH PASSENGER..

\begin{tabular}{lc}
\hline \multicolumn{1}{c}{ Max. AIS Score } & $\begin{array}{c}\text { Number of } \\
\text { Passengers }\end{array}$ \\
\hline AIS 6 - Unsurvivable & 0 \\
AIS 5 - Critical & 0 \\
AIS 4 - Severe & 1 \\
AIS 3 - Serious & 4 \\
AIS 2 - Moderate & 7 \\
AIS 1 - Minor & 32 \\
< AIS 1 & 43 \\
\hline Total & 103 \\
Average AIS & 1.4 \\
\hline
\end{tabular}

The non-fatal injuries sustained by passengers were brought about by either intrusion of the impacting equipment into the occupant volume or secondary impact with seats and other interior structures of the car. Available evidence suggests that the most serious injuries were a result of the former.

For instance, a passenger suffered the most severe injuries (maximum AIS of 5), including a renal vein avulsion, multiple liver and spleen lacerations, fractures of multiple spinous and transverse processes of the thoracic and lumbar spine, and head trauma that resulted in diffuse axonal injury (DAI), which often renders the subject comatose and frequently results in death [10]. This occupant was comatose for 22 days following the collision. While it was unknown in which car or seat this subject was initially located, a statement by a witness states that he was knocked out of his seat and hit by debris, suggesting that he was seated in one of the areas of lost survival space. 
Two passengers of car 148 sustained injuries due to intrusion of debris into the occupied volume. One passenger suffered a maximum AIS of 3 indicated by such injuries as pneumothorax of the left thoracic cavity, a cardiac contusion, significant lacerations to the head and scalp, and multiple fractures to the facial bones (specifically, LeFort I and II fractures) that resulted in pneumocephalus. This passenger is believed to have been seated facing forward on the left side of the car due to the magnitude of the facial fractures and the localized fractures to the left side of the body. Another passenger suffered a maximum AIS of 4 due to fractures of the right fourth through eighth ribs, facial fractures, open fractures of the right tibia and fibia, right upper and lower lobe lung contusions, and right transverse process fractures of the first through fourth lumbar vertebrae. This occupant reported that he was initially seated in a rear-facing window seat on the lower left side of car 148. During the impact, he was thrown across the aisle and impacted a forward-facing seat and was rendered unconscious. It is likely that he was impacted directly by the side wall of the car as it intruded into the occupied volume.

In general, the injuries related to secondary impact were less severe. The longitudinal acceleration environment was relatively benign, even on the cab car (625) that impacted the freight locomotive directly. One passenger of car 625 was seated in a forward-facing right-side window seat without a workstation table near the middle of the upper level. During the initial collision, this passenger was thrown forward and to the left, and ended up in an aisle seat on the left side of the car. This passenger suffered AIS 2 injuries including tears to the anterior cruciate ligament (ACL) and medial collateral ligament (MCL) of his right knee and the ACL and meniscus of his left knee, and sprains of both ankles due to impact and possible entrapment of his lower legs with the seat pan of the opposing seats. This passenger also suffered a mild concussion due to a head impact with an unknown surface, perhaps a seat frame or fellow passenger.

Some injuries resulted from the rolling of car 623, the trailing cab car of the northbound train, as the passengers on the left side of the car fell to the ground. One such passenger, who was seated on the left side of the rear mezzanine level, suffered AIS 2 injuries including a sub-capsular hematoma of the liver, a chest wall contusion, a mildly displaced anterior fracture of a right rib, and bruising of his chest and right leg. This subject was thrown forward into a workstation table, and rebounded back into his seat. As the car tipped onto his side, he held onto the leg of the table, letting go only when the car came to rest. Another passenger, seated in a forward-facing aisle seat on the left side of the upper level, suffered AIS 2 injuries including sprains of the cervical, lumbar, and thoracic spine, fractures of the T12 and L1 vertebrae, and a laceration to his chin. This passenger stated that he impacted his head, face, arm, and leg as he fell to the ground.

\section{DISCUSSION}

A review of the collision dynamics of the colliding equipment estimated that the longitudinal deceleration of both the southbound and northbound trains was significantly lower than the conditions to which the interior seating arrangements are designed. The occupants seated in the areas not affected by intrusion into the occupied volume of the car were subjected to lateral and vertical accelerations, which caused relative motion across the aisle, over seatbacks, and onto the floor - which, in the case of the trailing cab car of the northbound train which overturned, could have resulted in a fall from a height of up to 10 feet.

Despite the complex motions of the passenger vehicles involved, the principle causal mechanism for the fatalities and serious injuries that occurred in the Glendale incident was a loss of survival space. This causal mechanism describes both the gross deformation of the railcar structure and the accumulation of debris that results. While the nature of this incident makes it difficult to determine whether the injuries resulted from lost survival space or occupant impact with the interior structures of the railcar, it can be assumed that injuries to occupants that were initially seated in areas of sufficient intrusion to damage or destroy seats occurred due to a loss of survival space. A total of 688 square feet of occupied floor space was lost, 82 seats were missing, and an additional 32 seats were damaged due to structural deformation of the passenger rail vehicles. A secondary causal mechanism for injury was secondary impact of the occupants with interior seats and tables, though these injuries were generally less severe. Of all the injuries that occurred in areas where structural integrity was maintained, the maximum AIS was 2.

On July 21, 2009, FRA published a Notice of Proposed Rulemaking proposing that most passenger and many freight railroads install Positive Train Control (PTC) systems [11]. Such systems can be effective in preventing collisions between two trains on the same track and overspeed derailments. However, an obstacle on the right-of-way, such as the SUV that initiated the derailment of the southbound train in the Glendale incident, can be difficult for such systems to detect with sufficient time to stop the trains. PTC systems are also limited in their ability to prevent derailments caused by track and equipment defects. For system safety, both structural crashworthiness and interior occupant protection measures are necessary to mitigate hazards presented by unpredictable and unpreventable conditions.

\section{CONCLUSION}

A rail collision involving three trains in Glendale, California on January 26, 2005 led to eleven fatalities and many serious injuries. This incident was investigated as part of a field study of occupant injury in passenger train collisions and derailments currently being conducted at the request of the Federal Railroad Administration. The data collected at the scene, along with interviews with the passengers, assisted in an understanding of the events that transpired.

In summary, the Glendale incident resulted from three impacts. First, the leading cab car of the southbound train struck an SUV on the track south of the Chevy Chase Drive grade crossing. Second, the lead truck of the leading cab car followed the siding track and the southbound train impacted a standing freight locomotive. Finally, the cab car and the first coach car buckled laterally towards a northbound train, raking 
the side of two passenger cars. The second and third collisions resulted in a loss of occupied volume equivalent to the seating capacity of over 80 occupants. There were a total of eleven fatalities and 103 injuries as a result of this series of events.

At the time of the Glendale incident, METROLINK was preparing to purchase new equipment. As part of its response to the incident, METROLINK made an effort to apply recent results of the FRA research into passenger train crashworthiness to this procurement. In coordination with the American Public Transportation Association (APTA), METROLINK began collaborating with the FRA and the Federal Transit Administration (FTA). FRA, FTA, and APTA formed an ad hoc CEM Working Group in May 2005. This Working Group included participants from the rail industry, including passenger railroads, suppliers, labor organizations, and industry consultants. A detailed technical specification was developed in just over four months [2]. This rapid development was possible because of METROLINK's commitment, the availability of well-developed technical information, the sustained existence of Government/Industry committees committed to increasing railroad safety, and the support of the FRA, FTA, and APTA management and representatives. METROLINK released its specification, including the recommendations from the Working Group, on September 16, 2005, as part of an invitation for bid. The contract for equipment manufacturing was awarded to Rotem, a division of Hyundai, now Hyundai Rotem Company (Rotem). Rotem developed a shaped-nose, CEM design for the new METROLINK cab cars. A photograph of one of METROLINK's CEM cab cars is shown in Fig. 16. This equipment is planned to be put into service in December 2010.

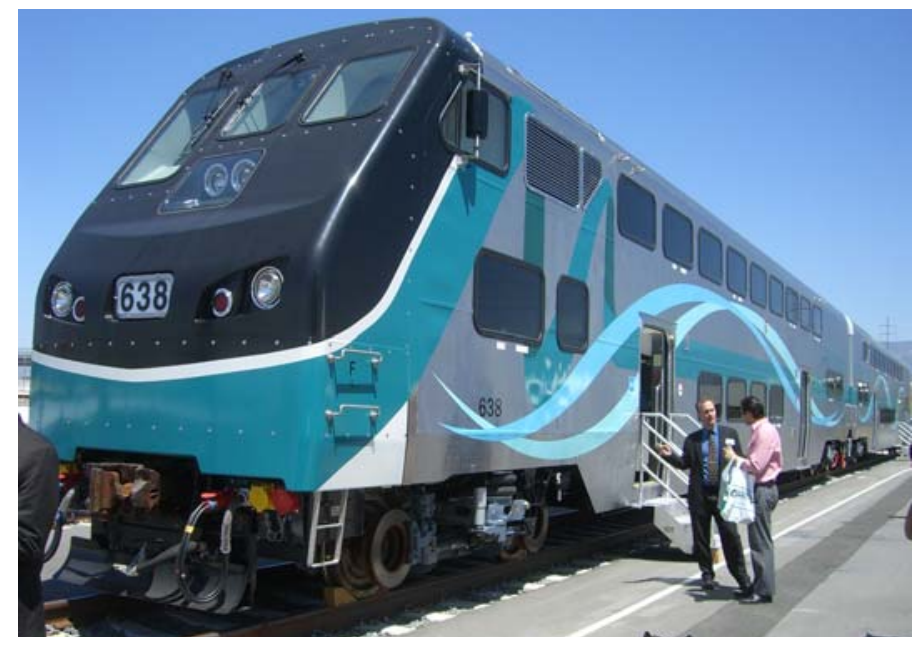

Fig. 16. ONE OF METROLINK'S CEM CAB CARS, BUILT BY HYUNDAI ROTEM.

\section{ACKNOWLEDGMENTS}

This work was done as part of the Federal Railroad Administration's Equipment Safety Research Program. At the time the work was performed, Dr. Tom Tsai was the FRA's Program Manager and Claire Orth was the Chief, Equipment and Operating Practices Division, Office of Research and Development. Both have since retired. Their former positions are currently held by Melissa Shurland and Kevin Kesler, respectively. The authors thank Grady Cothen, Deputy Associate Administrator for Regulations Development for coordinating the investigation. Mr. Cothen is also now retired. The authors would also like to thank Al Settje, FRA Regional Administrator, for his support and assistance in carrying out the investigation. And finally, the authors would like to thank Lieutenant Jon Perkins of the Glendale Police Department for allowing access to the accident site and providing ready access to the autopsy information.

\section{REFERENCES}

[1]. Tyrell, D., Jacobsen, K., Martinez, E., “A Train-to-Train Impact Test of Crash Energy Management Passenger Rail Equipment: Structural Results,” American Society of Mechanical Engineers, Paper No. IMECE2006-13597, November 2006.

[2]. Tyrell, D., Strang, J., Hynes, R., Peacock, T., Lydon, B., Woodbury, C.A., Stastney, J., "Development of a Crash Energy Management Specification for Passenger Rail Equipment" Compendium of Papers, 86th Annual Meeting, Transportation Research Board, Paper No. 070080 January 2007.

[3]. Parent, D., Tyrell, D., and Perlman, A, "Crashworthiness Analysis of the Placentia, Ca Rail Collision," International Journal of Crashworthiness, Vol. 9, Issue 5, pp. 527-534, September 2004.

[4]. Parent, D., Tyrell, D., Rancatore, R., Perlman, A.B., "Design of a Workstation Table with Improved Crashworthiness Performance," American Society of Mechanical Engineers, Paper No. IMECE2005-82779, November 2005.

[5]. Severson, K., Parent, D., "Train-to-Train Impact Test of Crash Energy Management Passenger Rail Equipment: Occupant Experiments,” American Society of Mechanical Engineers, Paper No. IMECE2006-14420, November 2006.

[6]. Molloy, T., "Suicide attempt triggers California commuter rail tragedy that kills 10, injures more than 180," Associated Press Archive, January 26, 2005.

[7]. National Transportation Safety Board, "Railroad Accident Report: Collision of Burlington Northern Santa Fe Freight Train With Metrolink Passenger Train, Placentia, California, April 23, 2002.” RAR-03-04, October 7, 2003.

[8]. Parent, D., Tyrell, D., Perlman, A.B., "Evaluating Abdominal Injury in Workstation Table Impacts," Compendium of Papers, 84th Annual Meeting, Transportation Research Board, January 2005.

[9]. Association for the Advancement of Automotive Medicine, "The Abbreviated Injury Scale: 2005 revision (AIS-05)” 2005.

[10]. Wolf, J., Stys, P., Lusardi, T., Meany, D., and Smith, D., "Traumatic axonal injury induces calcium influx modulated by tetrodotoxin-sensitive sodium channels," Journal of Neuroscience, 21(6), pp. 1923-1930, 2001.

[11]. 49 CFR Parts 229, 234, 235 et al. Positive Train Control Systems; Proposed Rule, Federal Register, Vol. 74, No. 138, Federal Railroad Administration, Department of Transportation, Tuesday, July 21, 2009. 